the second and third operations the placenta was found attached, as at the first, above and behind, and it and the membranes peeled off just as readily. The cord was not tied off for two or three minutes, then the child was put to the breast as soon as it had been washed; it was afterwards suckled without any other food being given. All three babies throve without a break.

The nterus began to contract immediately it was squeezed the contraction was just as quick on the second and third occasions, as at the first when labour had already commenced. After a long strip of gauze had been drawn down and out through the vagina, the uterine wound was sewn up by a double row of interrupted kangarootendon sutures. When this had been completed the uterus had become quite hard, and no blood could be squeezed out between the sutures. Then the abdominal wall was as carefully sutured with three rows of interrupted kangarootendon sutures and a continuous fine silk suture through the skin. By far the longer part of each operation was occupied by the insertion of the sutures.

As for the patient during and after the three operations, it was the same as if she had been operated upon for an nncomplicated ovarian cyst. The lochia and the involution of the uterus offered no differences from a normal labour.

The photograph shows the mother with her three daughters after recovery from the third Cæsarean section. She then had a perfectly sound abdominal scar.

Portland-place, $\mathbf{W}$.

\section{A CASE OF GUMMA OF THE ENTIRE LEFT LUNG.}

By Robert Halt, Jun., M.B., B.CH., B.A.O. Belf. CAPTAIN, R.A.F.; AND LATELY SURGEON PROBATIONGR, R.N.V.R.

THE following case may be of interest on account of the rarity of the condition :-

Patient, aged 40; family history good, no malignancy, married, and has three children living. He states that they are healthy; a fourth child died of "convulsions" at the age of 10 months. He is, and was, a moderate drinker and smoker. $\mathrm{He}$ is a labourer in a flour-mill and attributed his present condition to an accident in July, 1914. Several bags of flour fell on him and he was away from work for a month; he felt breathless and easily tired upon slight exertion, and had a severe pain in his back, left shoulder and left arm. He returned to light work, but frequently had to rest. His appetite became impaired and he had a cough. The dyspncea gradually became more marked, and after several periods of alternate work and "lying up" he entered hospital in June, 1918, when his condition was as follows: -

Patient complained of constant pain in his left side, left shoulder and back, also shortness of breath and a cough with tough spit, which was very difficnlt to get up. (It was not blood-stained or prune-coloured.) Very little exertion exhausted him, and he had headaches. His appetite was poor, but he had not lost weight to any considerable extent during the past year.

Patient was emaciated and pale, and did not speak dis tinctly. His teeth were very bad, and there were "snail track" ulcers to the right of his uvula. The abdomen and bowels were normal. The heart was hypertrophied downwards to the sixth rib, and outwards to the left $2 \frac{1}{2}$ inches beyond the nipple line. The impulse was of a heaving type, and a diastolic murmur was heard in the aortic area with maximum intensity at Erb's point, and conducted to the apex. The electrocardiograph showed predominance of the left ventricle. The pulse was 108 and "Corrigan's": the condition of the artery walls was fair. Epigastric and jugular pulsation was present. Blood pressure : Right arm, systolic 120 , diastolic 76 ; left arm, systolic 106 , diastolic $68 \mathrm{~mm}$. Hg. Respirations were shallow and 40 per minute. The movement of the left side of chest was impaired. Vocal fremitus was absent over the entire left lung," stony" dullness over whole left lung, and vocal resonance absent except over a small area extending from the sterno-clavicular junction to a distance of about 21 inches in radius. In this area there was amphoric resonance. The nervous and genito-urinary systems were normal and pyrexia was not present.

The patient denies having had spphilis, but Wassermann reaction was markedly positive. He was put on antisyphilitic treatment, and under large doses of potassium lofide his cough and breathlessness have been very mach relieved. The possibility of actinomycosis was considered and ruled out.

In conclusion, I wish to express my thanks to my father, Dr. R. Hall, for permission to examine and take the history of this case.

\section{Mteditual Societies.}

\section{MEDICAL SOCIETY OF LONDON.}

Reconstruction in Medical Fducation and Practice.

AT the ordinary meeting of the society held on Dec. 2nd, A the presidency of Dr. ARTHUR F. VOELCKER

Mr. H. J. W ARING (Col. R.A. M.C.) introduced a discussion on Reconstruction in Medical Education and Practice. It was, he said, impossible to divorce medical education from medical practice. The objects to be aimed at in medical reconstruction could be put in the following brief form : (1) to improve the education of students so as to make them more efficient for medical practice; (2) to improve the conditions under which medical practice is carried on; (3) to obtain the largest output of good work from medical men with the least expenditure of energy; (4) so to arrange the conditions of medical practice that the practitioner could have more time for recreation and more opportunities for bringing his medical knowledge up to date. He was assuming that it was not the intention of the State to create a whole-time medical service; the draft Bill did not foreshadow that.

The Hedical Curriculum.

Five years was too short a period of study if clinical subjects were to be adequately taught. When, in 1892, the medical curriculum was lengthened to five years it was the intention that the added year should be devoted to clinical work, but owing to some deficiencies in organisation and to some matters concerning the organisation of the schools the preliminary subjects still occupied the whole period. Two suggestions had been made to remedy that. The first was that the chemistry, physics, and biology course shuuld be completed before the commencement of medical study; this could be done by rearranging the work at the public and secondary schools in the case of students who did not go to the older universities. In many public schools the courses of instruction were so arranged that the chemistry, physics, and biology tanght sufficed for the first examination; the same was also true. to a lesser extent, of many secondary schools. If the need were made very clear the public schools would also fall into line. In Scandinavia the period of study had been extended to six years, and he was told by medical men there that it was satisfactory; but he thought the better solution of the difficulty was the completion of the chemistry, physics, and biology before entering the five-year course of medicine and surgery

Medical Eduoation.

He felt that anatomy should be taught by professed anatomists, but taught less from the morphological than from the surgical side. These professors should be shown the need for emphasising the latter aspect-i.e., in the use of the living model and the normal $X$ ray appearances, especially in regard to the bones. It was also absolutely necessary to teach the lymphatic system of the body more thoroughly. There should be a schedule of anatomy, for some parts need not be taught in detail, such as learning every individual muscle of the back. Owing to the pancity of material, he thought it necessary that there should be a new Anatomy Act; and if that were the general view there should be a collective representation made, for the present was an opportune time. Applied anatomy would have a fitting place during the clinical period, and should be taught by a surgeon. Physiology had become such an enormons subject that its professors showed a tendency to teach it as a science apart, rather than human physiology as a factor in general medicine. The chemist should be attached to this department, and the time had now arrived for the general inclusion of a biochemist. Pharmacology should be taken in the intermediate period, in close association with physiology. He thought that the essentials of bacteriology should be tanght before the student commenced his actual medical work; it could be done in a compulsory three months' elementary pathology and bacteriology course.

With regard to materia medica the student had an enormous amount to learn, as the Pharmacopceia was now very extensive. A number of physicians and surgeons could probably cut it down to one-half with advantage to the 